\title{
PROFESSIONAL POSTGRADUATE TRAINING OF FAMILY DOCTORS - AN IMPORTANT PART AND CONDITION OF THE OPTIMAL PALIATIVE AND HOSPISE CARE SYSTEM IMPLEMENTATION IN UKRAINE
}

DOI: 10.36740/WLek202005116

\author{
Vasyl M. Mykhalchuk, Nina G. Goida, Anatolii V. Tsarenko \\ SHUPYK NATIONAL MEDICAL ACADEMY OF POSTGRADUATE EDUCATION, KYIV, UKRAINE
}

\begin{abstract}
The aim: To substantiate measures of optimization of the system of postgraduate training of GPs-Family Doctors (GP-FDs) on providing palliative and hospice care (PHC) in outpatient settings.

Materials and methods: Regulatory documents of Ukraine and International Professional Organizations; domestic and foreign literary sources; official statistics data; results of sociological research. The research methods were used: biblio-semantic, sociological (questionnaires), systemic approach and systemic analysis, and conventional medicalstatistical methods.

Results: Based on the analysis of regulatory documents, the socio-medical importance of PHC and the importance of GP-FDs on PHC are shown. The results of the sociological survey determine: the estimated needs for PHC in Ukraine; insufficient number of inpatient beds for palliative patients (PPs); the absence of a PHC-mobile-teams service, which necessitates the involvement of GP-FDs for PHC at home. The results of the survey indicate an insufficient level of knowledge and an urgent need for special PHC education of GP-FDs. Conclusions: Multidisciplinary professional training for GP-FDs is of great importance for creating a PHC System. This will allow GP-FDs, together with social workers, NGOs to provide comprehensive PHC to PPs and their families, including medical, psychological, social and spiritual components.
\end{abstract}

KEY WORDS: Health Care System; palliative and hospice care; Palliative and Hospice Care System; palliative patients; Primary Medical Care; General Practitioners-Family Doctors

Wiad Lek. 2020;73(5):925-930

\section{INTRODUCTION}

Today, in many countries, including Ukraine, the problem of creating and developing an optimal Palliative and Hospice Care (PHC) System has become one of the most important medical and social problems and one of the most prioritized social and humanitarian tasks for governments and society. The experience of many countries in the world strongly demonstrates that PHC most adequately provide the needs and life quality of palliative patients (PPs) and their relatives, and promote their right to health and preserve their human dignity at the end of life [1-6].

The current concept of an effective PHC-delivery system is that it is the duty of governments of all states to ensure the qualified and professional PHC to patients with life-threatening and life-limiting diseases, regardless of social status, gender, age, place of PPs residence and their families. This is due to the aging of the population, a steadily increasing number of patients with chronic incurable progressive diseases, including a limited life expectancy. [1-6].

General Practitioners-Family Doctors (GP-FDs) play an important role in $\mathrm{PHC}$ providing to the population, as almost $80 \%$ of PPs, even in the USA and Europe, receive palliative care at home. This requires the creation and optimization of a postgraduate training system for GP-FDs on PHC provision. [2; 4; 7-10].

\section{THE AIM}

The aim was to substantiate optimization measures of professional postgraduate training system of GP-FDs on the $\mathrm{PHC}$ providing to the population on an outpatient basis and at home.

\section{MATERIALS AND METHODS}

The work used regulatory documents of Ukraine and International Professional Organizations, performed a literary review in the search systems JAMA, Scholar and PubMed, as well as in domestic and foreign literary sources, data from the Ministry of Health of Ukraine of ficial statistics and the a sociological survey results using our developed questionnaires. 33 physicians working in specialized inpatient $\mathrm{PHC}$ healthcare facilities (HFs) of (group 1) and 415 medical professionals $(\mathrm{m} / \mathrm{p}$ ) of non-specialized HFs (group 2) were questioned. We used the following research methods: bibliosemantic, sociological (questionnaires), systematic approach and systematic analysis. In the statistical processing of materials we used conventional medical-statistical methods. The methods that were used are approved by the ethics committee of the Shupyk National Medical Academy of Postgraduate 
Education. All procedures were carried out in accordance with the ethical standards of the responsible committee on human experimentation and with the Helsinki Declaration (6th, rev., 2008, Seoul) and the Universal Declaration on Bioethics an Human Rights (2006) as key documentation considering ethical decision making and conceptualization for the article's scientific content.

\section{RESULTS}

Today, in Ukraine, the basis of the regulatory framework governing the formation and development of the PHC system is, first of all, the Constitution of Ukraine, in particular Articles 3, 27, 28 and 49, and the Law of Ukraine "Fundamentals of Legislation of Ukraine on Health Care" of 19.11.1992 No. 2801-XII, which in 2011 introduced a separate type of medical care - "palliative care" (Articles $\left.8,33,35^{4}\right)$, that can be considered as a new stage of the domestic Healthcare System development. For the first time in the Ukrainian history, palliative care was recognized as a separate type of medical care at the legislative level. Also, the Law of Ukraine "On State Financial Guarantees of Medical Services to the Population" of October 19, 2017 No. 2168-VIII (Article 4) says that the state guarantees citizens full payment from the State Budget of Ukraine for the medical services and medicines they need in palliative care.

Important regulatory documents on the $\mathrm{PHC}$ providing are the Orders of the Ministry of Health of Ukraine: dated April 25,2012 , No. 311, which approved the "Unified clinical protocol of palliative care in chronic pain syndrome, developed on the basis of adapted clinical guideline "Pain control"; dated 21.01. 2013 No. 41 "On the palliative care organization in Ukraine"; dated 19.03.2018 No. 504 "On approval of the Procedure of rendering primary medical care" and dated 29.07.2016 No. 801 "On approval of the Regulations of primary medical care center and outpatient clinic and their provisions".

The importance of professional PHC training and continuous professional development of $\mathrm{m} / \mathrm{p}$, especially physicians, is emphasized in the main international documents for PHC organization, in particular, "Recommendation Rec (2003) 24 of the Committee of Ministers to member states on the organization of palliative care"; Guidelines "Palliative care: WHO recommendations for effective programs" - Module 5 of the series "Fighting cancer: knowledge - into practice" (2007); the EAPC Guidelines "White Paper on standards and norms for hospice and palliative care in Europe" (2009, 2010), the Prague Charter "Palliative Care - A Human Right" (2013) and others.

As early as 1990, WHO recommended:

- to include in the training programs of all $\mathrm{m} / \mathrm{p}$ the basic principles and provisions of $\mathrm{PHC}$ and the basic principles and approaches of chronic pain syndrome (ChPS) control;

- to carry out postgraduate $\mathrm{PHC}$ trainings of $\mathrm{m} / \mathrm{p}$ at higher medical education establishments with the issuance of a certifying;

- to involve leading PHC specialists to train health practitioners of various specialties and medical students in each country, etc. $[1 ; 10]$.
The analysis of medical and demographic data made it possible to determine the estimated need of the population in Ukraine for PHC using the coefficient 0.8 of the deaths number recommended by WHO and EAPC. In January 1, 2018, the estimated need for PHC in Ukraine was 457.1 thousand people, or 1078.4 per 100 thousand of population. Of these people, $78.9 \%$ of PPs are persons over 60 years, those with maximum level needs $(34.5 \%)-80$ years old and older. The estimated need for a stationary PHC (with a population of 42,415 million people in Ukraine at the beginning of 2018) was about 4.25 thousand beds. According to the results of our sociological survey, the actual number of beds for PPs in Ukraine (in 01.01 .2018 ) was 4258 beds, which is $70.4 \%$ of the needed. The total number of PPs whom a stationary PHC was provided in 2017 was 20.5 thousand people, or 65.6 per 100 thousand of population, which is $40.6 \%$ of the estimated need for a stationary PHC.

In some regions, no hospice, $\mathrm{PHC}$ unit or PHC-mobileteam have been established yet. Thus, in Ukraine there is an extremely insufficient number of in-patient beds for PP in PHC HF, and, practically, there is no outpatient and visiting PHC service at home - there are 11 PHC-mobile-teams in total. This leads to the situation that PPs, especially in rural areas, do not have access to the specialized PHC.

This necessitates the involvement of GP-FDs, physicians and nurses in primary medical care (PMC) for PHC providing in outpatient conditions and at home. The results of research of the PHC delivery experience to patients at home in Poland, Slovakia, Moldova, Hungary and other countries have shown that this form is widely spread as the most affordable and economically viable one.

At the same time, the analysis of the questionnaires revealed a lack of knowledge and competence of healthcare professionals on the organization and provision of $\mathrm{PHC}$ - most doctors and even health care managers consider themselves not sufficiently educated for this function. Thus, $96.2 \pm 2.7 \%$ of interns, $76.7 \pm 6.4 \%$ of doctor-specialists, $70.9 \pm 7.2 \%$ of GP-FDs/PMC physicians and $65.5 \pm 8.8 \%$ of health care managers noted their incompetence as the organizer/manager of multidisciplinary PHC in outpatient settings, including at home. To the question "Do you have any special knowledge about providing $\mathrm{PHC}$ to the population?" was noted that they have no specific knowledge about this (interns - 64.8 $\pm 8.2 \%$, and GP-FDs/PMC physicians $-56.6 \pm 4.7 \%$ ). (Figure 1 ).

An analysis of the answers about where did respondents obtain their knowledge about PHC showed that only $9.1 \pm 5.0 \%$ of PHC HF physicians and $7.0 \pm 1.3 \% \mathrm{~m} / \mathrm{p}$ of non-specialized HF stated that was "during undergraduate studies at higher medical educational institutions". Therefore, higher medical education institutions pay insufficient attention to $\mathrm{PHC}$ education.

The urgent need for special knowledge in the provision of PHC is also evidenced by the results of our sociological survey. The overwhelming majority of respondents $-84.8 \pm 6.2 \%$ of PHC HF physicians and $79.0 \pm 2.0 \% \mathrm{~m} / \mathrm{p}$ of non-specialized HF indicated that they needed special 

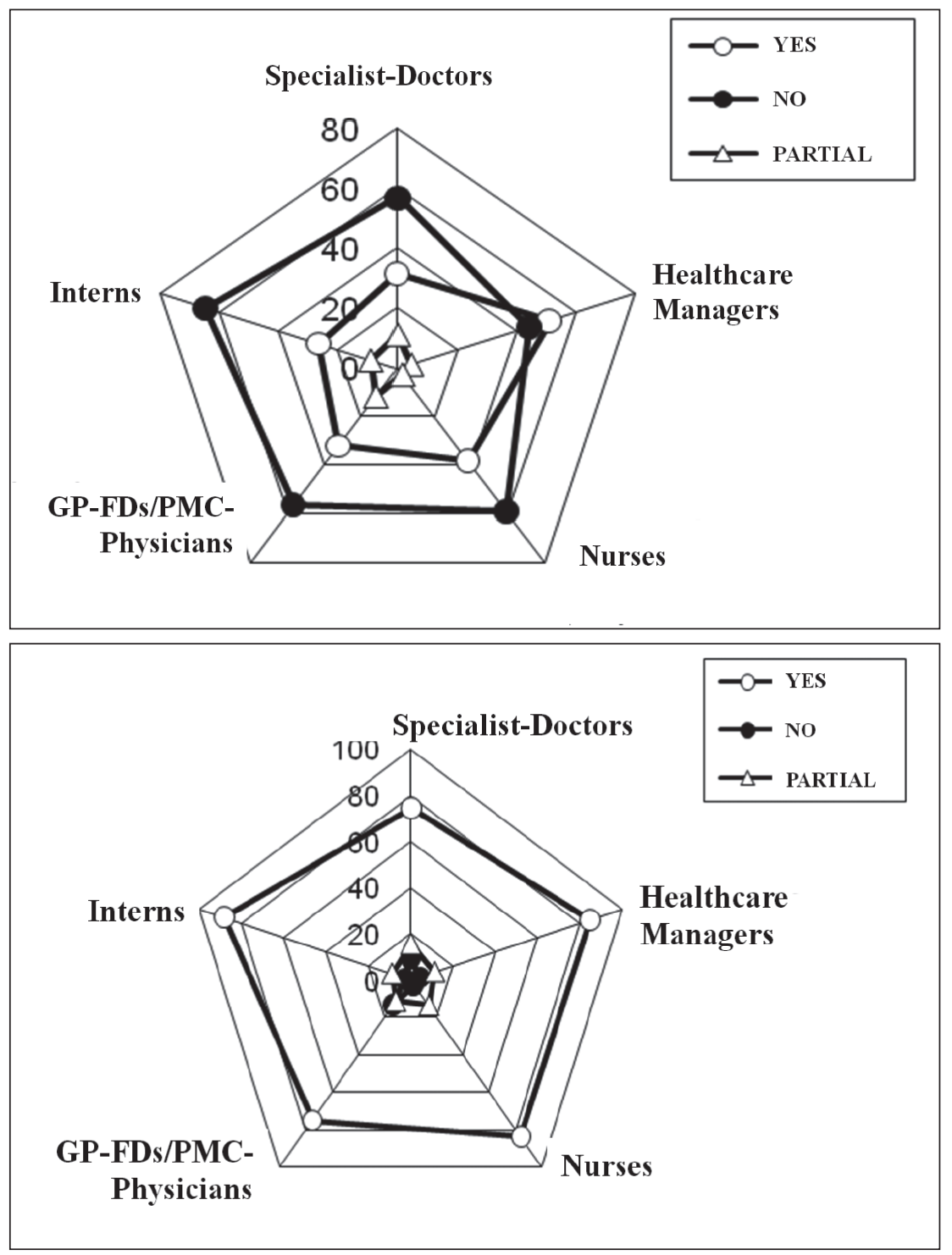

Fig. 1. Results of a sociological survey of healthcare professionals on the question "Do you have any specific knowledge about PHC providing to the population?"

Fig. 2. Results of a sociological survey of healthcare professionals - answers to the question "Do you feel the need in specific knowledge about PHC providing to the population?" depending on a specialty. knowledge about PHC provision. Depending on the specialty, the most convinced of the need for the special knowledge were interns $-88.2 \pm 5.5 \%$, health managers $84.4 \pm 5.4 \%$ and nurses $-84.0 \pm 4,1 \%$, specialist-doctors $-75,4 \pm 3,6 \%$ and GP-FDs/PMC physicians $-75,2 \pm 4,1 \%$. (Fig. 2).

The analysis of the questionnaires also shows the lack of understanding and significant underestimation by the respondents of the role of GP-FDs in ensuring the PHC provision. Only $54.5 \pm 8.7 \%$ of the respondents in Group 1 and $54.9 \pm 2.4 \%$ of Group 2 indicated that GP-FDs/PMC physicians should be involved in the PHC provision. Although, according to current international approaches and standards, it is GP-FDs/PMC physicians who should provide PHC to PPs and their families on an outpatient basis, including at home, which is the most affordable and economically viable form of PHC in many countries.

The results of the questionnaire analysis also indicated that the question "Do you want to work with palliative (incurable) patients?" was answered as "No" by $62.84 .5 \%$ of GP-FDs/PMC physicians, by $52.9 \pm 5.6 \%$ of nurses and by $45.8 \pm 4.2 \%$ of specialist-doctors. (Fig. 3 ). Depending on the respondents' work experience in medicine, the highest percentage of those who do not wish to work with palliative (incurable) patients $(59.7 \pm 6.2 \%)$ was among the $\mathrm{m} / \mathrm{p}$, who have been working in medicine for up to 5 years, and the lowest $(33,3 \pm 12,2 \%)$ - among $\mathrm{m} / \mathrm{p}$ with work experience of 46 and more years. (Fig. 4).

\section{DISCUSSION}

The results of our research have shown that the leading role in the PHC delivery in Ukraine should be played by the GP-FDs/PMC physicians together with the specialized PHC HFs, as foreseen by the concept of health care reform. This requires the professional training of relevant specialists - doctors and nurses. Particularly urgent issue is the postgraduate professional training of GP-FDs and nurses for the PHC provision at the primary level of medical care, particularly in the outpatient setting, including at home.

When PHC providing is in an outpatient setting and at home, GP-FDs/PMC physicians should be aware of and 

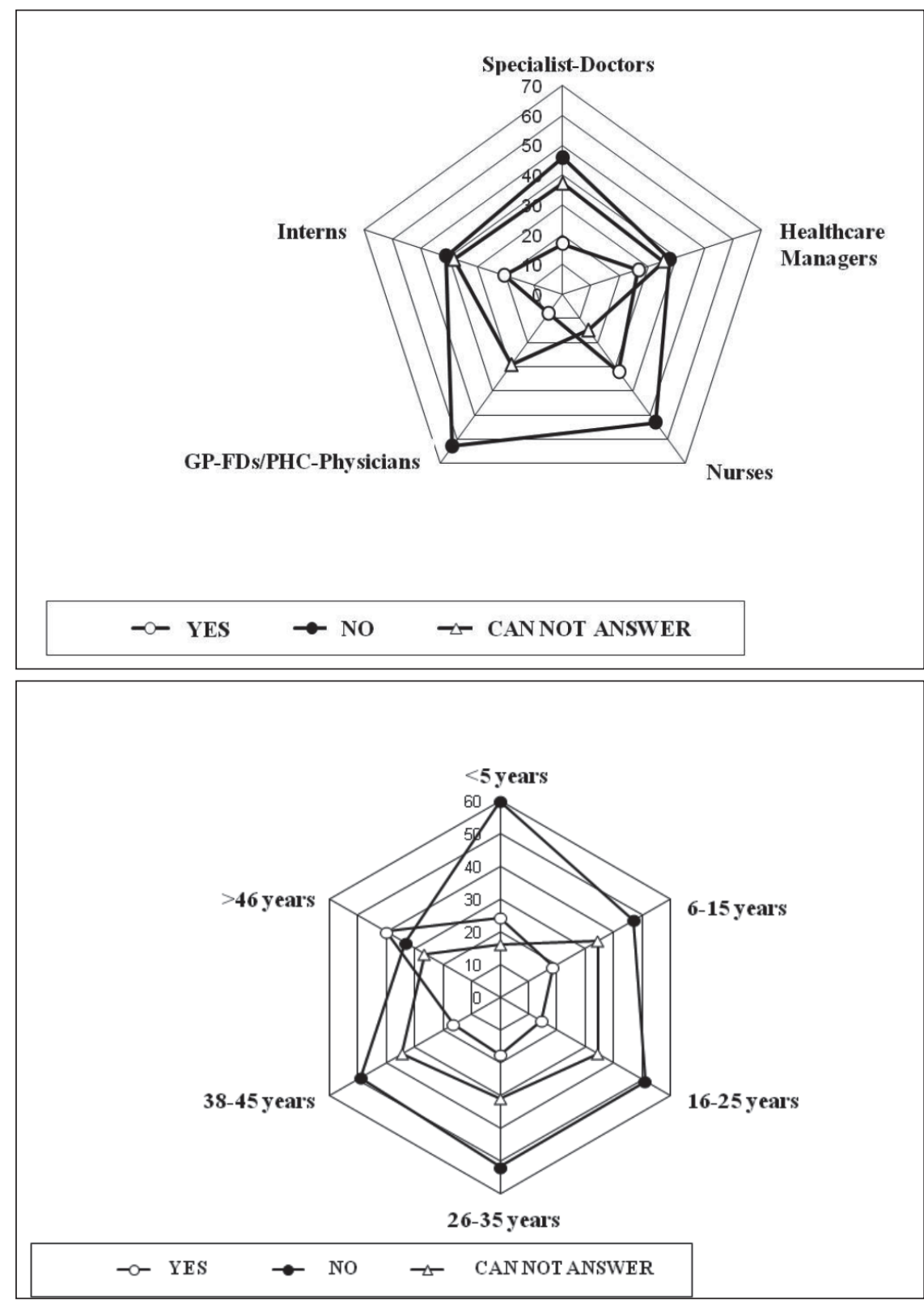

Fig. 3. The results of a sociological survey on the desire to work with palliative (incurable) patients of medical professionals in non-specialized HF, depending on their specialty.
Fig. 4. Results of a sociological survey on the desire to work with palliative (incubated) patients of medical professionals in non-specialized HFs, depending on the respondents' work experience in medicine. take into account basic principles and current international approaches to $\mathrm{PHC}$ :

- PHC, in particular, ChPS or other severe symptoms control should be available around the clock, regardless of the patient's place of residence/stay and social status.

- PHC foresees the PPs right to choose the PHC place and can be provided on a permanent basis in HFs of any ownership form, in specialized PHC facilities, in particular hospices, palliative and hospice departments, nursing hospitals and long-term care units, day care centers and at home.

- The needs of PPs and their families should be maximally met by the multidisciplinary-team approach based on their consent and wishes.

- PHC provides the PPs with the right to receive complete and truthful information about their illness and with their consent to provide this information to family members.

- PPs and their families are provided with accessible and comprehensible information on care, treatment, psychological and social support.

Based on the above mentioned, the main objectives of PHC providing in an outpatient setting and at home are:

- palliative treatment, ChPS and other symptoms of a disease relief / control;

- ensuring the fullest possible full-fledged active life of PPs and the proper quality of patients and their families life, affirmation of a life and a death as a natural process; - psychological and social support for the family during the illness of PP and during the period of a severe grief after the death of the patient;

- teaching family members the skills of caring and alleviating the PP's suffering;

- establishing partnerships between PPs and other professionals involved in the PHC providing;

- ensuring the right of the PPs to autonomy and making their informed decisions. 
Thus, modern PHC have high requirements to a GP-FD, which must have a strong knowledge of clinical medicine, pharmacology and psychology, have communication skills, be responsive and compassionate, be able to work in a team, because the basis of modern $\mathrm{PHC}$ is patient-family-oriented paradigm and multidisciplinary-team-work approach; medical and social staff, psychologists, lawyers and clergy, PPs and their relatives, representatives of non-governmental and charitable organizations, government and municipality authorities are also involved to the process of PHC providing.

It is the multidisciplinary and the cross-sectoral approach of PHC providing to the population, as well as the competent approach in the $\mathrm{m} / \mathrm{p}$ training, that the personnel of the Shupyk NMAPE Palliative and Hospice Medicine Department use to form the basis of training curricula on topical PHC issues. During 10 years of activity, teachers of the Department, based on the best modern international and national clinical and scientific-pedagogical experience, have developed 15 training curricula and conducted about 100 training courses, and have upgraded the skills of almost 3000 physicians and nurses from many regions of Ukraine. These approaches and principles were also taken into account in the Department staff formation by specialists of different profiles, in particular: oncologist, gerontologist, therapist, medical psychologist, psychotherapist, clinical pharmacologist, health manager, HIV/AIDS and TB-doctors and social work specialist.

In 2017-2019, with the participation of the Department's staff, a textbook "Palliative and Hospice Care" was published, that was recommended by the Ministry of Health of Ukraine for students and interns, and such manuals as "Current Issues of Palliative and Hospice Care in General Practitioners-Family Doctors Practice" and "Palliative Care: Organizational, Pharmaceutical, and Clinical Aspects of Pain Control" that will certainly improve the PHC trainings.

Thus, the above mentioned points to the importance and necessity of implementing a system of continuous professional education on PHC, in particular for GP-FDs.

\section{CONCLUSIONS}

1. Establishment and implementation of an affordable, high-qualified and effective PHC in Ukraine places high demands for health personnel, who must have a thorough knowledge of various aspects of clinical medicine, pharmacology and psychology, have communication skills, be sensitive and compassionate, be able to work in a team, because the concept of the modern PHC system in Ukraine is based on the patient-family-oriented paradigm, multidisciplinary, interagency and cross-sectoral approaches.

2. The leading role in the PHC providing, along with specialized PHC HF, should be played by PMC HF staff, and first of all by GP-FDs, as envisaged by the concept of reforming Ukrainian Health Care System, which requires the professional training of physicians and nurses for the PHC provision on an outpatient basis, including at home.

3. Today in Ukraine postgraduate PHC training for health professionals is an urgent problem that is an important component and condition for the implementation of an optimal PHC System and ensuring the accessibility of professional and qualified PHC to the population. This needs an attention and a support from the Ministry of Health of Ukraine.

4. The multidisciplinary professional training of GP-FDs, based on a competency-based approach, is of great importance for improving the quality of $\mathrm{PHC}$ provision to the population. Such training will enable GP-FDs, together with social work professionals, non-governmental and charitable organizations representatives to provide a comprehensive PHC to PPs and their families, including medical, psychological, social and spiritual components, as well as legal support. The implementation of a PHC Postgraduate Education System will ensure adequate quality of life for palliative patients and their families.

5. In embarking on the path of integration into the European Community, Ukraine should take into account international experience in the training and involvement of GP-FDs/PMC physicians/healthcare providers in a delivering PHC at home, which is of particular importance today in the context of scarce resources.

\section{REFERENCES}

1. WHO. Strengthening of palliative care as a component of comprehensive care throughout the life course. The Sixty-seventh World Health Assembly.WHA67.19. EB134/28.24May 2014; 5. Available from: http:// apps.who.int/gb/ebwha/pdf_files/WHA67/A67_R19-en.pdf.

2. Siouta N., Van Beek K., van der Eerden M. E., and al. Integrated palliative care in Europe: a qualitative systematic literature review of empiricallytested models in cancer and chronic disease. BMC Palliat Care. 2016; 15: 56. doi: 10.1186/s12904-016-0130-7. PMCID: PMC4939056. Available from: https://www.ncbi.nlm.nih.gov/pmc/articles/PMC4939056/.

3. WHPCA and WHO. Global Atlas of Palliative Care at the End of Life. Edited by S. R. Connor, M. C. S. Bermedo. World Health Organization. 2014; 111.

4. Shekera 0. G., Tsarenko A. V. Medical and social grounds for the functional and organisational model of palliative and hospice care system at the primary health care level in Ukraine. Sănătate Publică, Economie și management în Medicină. Chișinău. 2019; 4(82): 239-245.

5. Knyazevych V., Tsarenko A., Bratsyun 0. Palliative and hospice care on the right track in Ukraine. European Journal of Palliative Care. 2013;4(20):202-205.

6. Arias-Casais N., Garralda E., Rhee J.Y., et al. EAPC Atlas of Palliative Care in Europe 2019. Vilvoorde: EAPC Press; 2019.

7. Standing H, Jarvis H, Orr J, Exley C, Hudson M, Kaner E, Hanratty B. How can primary care enhance end-of-life care for liver disease? Qualitative study of general practitioners' perceptions and experiences. BMJ 2017 1;7(8):e017106. doi: 10.1136/bmjopen-2017-017106. PMID: 28864486. Available from: https://www.ncbi.nlm.nih.gov/pmc/ articles/PMC5588936/.

8. Connor S. R. Hospice and Palliative Care: The Essential Guide. New York, 2009. NY: Routledge. 2009; 262.

9. Connor S. R., Downing J., Marston J. Estimating the Global Need for Palliative Care for Children: A Cross-sectional Analysis. J. Pain Symptom Manage. 2017; 53(2): 171-177. doi: 10.1016. 
10. Integrating palliative care and symptom relief into primary health care: a WHO guide for planners, implementers and managers. Geneva, Switzerland, 2018; 88.

The work was carried out in the framework of research works: The Department of Healthcare Management of the Shupyk National Medical Academy of Postgraduate Education "Substantiation of management models of health care subsystems and health strengthening of Ukrainian population in accordance with the European strategies" (state registration number 0115U002160, deadline: 2014-2019).

\section{ORCID and contributionship:}

Vasyl M. Mykhalchuk - 0000-0002-5398-4758 ${ }^{A, B, D, F}$

Nina G. Goida - 0000-0001-6625-0078 A,E,F

Anatolii V. Tsarenko - 0000-0002-1617-3673 ${ }^{\text {B,C,D }}$

\section{Conflict of interest:}

The Authors declare no conflict of interest

\section{CORRESPONDING AUTHOR} Vasyl M. Mykhalchuk

Department of Public Health Management,

Shupyk National Medical Academy of Postgraduate Education 9 Dorohozhytska Str., 04112 Kyiv, Ukraine

tel: +380973885108

e-mail: shepit@ukr.net

Received: 28.01.2020

Accepted: 30.03 .2020

A - Work concept and design, B - Data collection and analysis, C - Responsibility for statistical analysis,

$\mathbf{D}$-Writing the article, $\mathbf{E}$-Critical review, $\mathbf{F}$ - Final approval of the article 